\title{
HUBUNGAN KEPATUHAN PERAWAT DALAM MELAKUKAN HAND HYGIENE TERHADAP KEJADIAN PHLEBITIS DI RUANG RAWAT INAP RUMAH SAKIT UMUM DAERAH TGK CHIK DITIRO SIGLI KABUPATEN PIDIE, ACEH
}

\section{EFFECT OF NURSE COMPLIANCE IN HAND HYGIENE TO THE INCIDENCE OF PHLEBITIS IN INPATIENT ROOM AT TGK CHIK DITIRO SIGLI REGIONAL GENERAL HOSPITAL, PIDIE REGENCY, ACEH}

\author{
Idawati $^{1}$, Rita Mirdahni ${ }^{2}$ \\ ${ }^{1,2}$ Program Studi D-III Kebidanan STIKes Medika Nurul Islam \\ Email : pon_ida@yahoo.co.id
}

\begin{abstract}
ABSTRAK
Kepatuhan perawat dalam mencegah terjadinya infeksi nosokomial merupakan stimulasi yang dapat menimbulkan respon emosional perawat terhadap upaya universal precaution yang akan meningkatkan upaya penurunan kejadian infeksi nosokomial. Menjaga kebersihan tangan dengan baik dapat mencegah penularan mikroorganisme dan menurunkan infeksi nosokomial atau phlebitis. Tujuan penelitian ini adalah untuk mengetahui hubungan kepatuhan perawat dalam melakukan hand hygiene terhadap kejadian phlebitis. Metode penelitian analitik dengan pendekatan cross sectional, pada penelitian ini populasi adalah seluruh perawat di Ruang Rawat Inap Rumah Sakit Umum Daerah Tgk Chik Ditiro dengan jumlah sampel sebanyak 83 perawat. Hasil penelitian menunjukkan bahwa 37 responden berusia 20-30 tahun (45\%), 38 orang berpendidikan S1 (46\%), 50 responden berjenis kelamin laki-laki (60\%) dan 56 responden berstatus PNS (67\%), responden yang tidak patuh melakukan hand hygiene sebanyak 50 orang $(60 \%)$. Hasil Uji statistik didapatkan nilai p-value = $0,000<\alpha \quad 0,05$ yang artinya terdapat hubungan antara kepatuhan perawat dalam melakukan hand hygiene terhadap kejadian phlebitis. Kesimpulan ada hubungan antara kepatuhan perawat dalam melakukan hand hygiene terhadap kejadian phlebitis di ruang rawat inap Tgk. Chik Ditiro Sigli Kabupaten Pidie. Saran diharapkan pihak rumah sakit agar lebih sering melakukan sosialisasi dan pelatihan tentang hand hygiene dalam upaya menurunkan kejadian phlebitis serta diharapkan kepada perawat agar lebih patuh dalam melakukan hand hygiene sesuai dengan peraturan/SPO yang telah ditetapkan dirumah sakit khususnya tentang kebersihan tangan.
\end{abstract}

Kata Kunci: Kepatuhan Perawat, Hand Hygiene, Phlebitis

\begin{abstract}
Nurses 'compliance in preventing nosocomial infections is a stimulation that can cause an emotional response to nurses' universal prevention efforts that will increase efforts to reduce the incidence of nosocomial infections. Maintaining good hand hygiene can prevent transmission of microorganisms and reduce nosocomial infections or phlebitis. The purpose of this study was to see the relationship between nurses in carrying out hand hygiene against the incidence of phlebitis. Analytical research method with cross sectional approach, in this study the population was all nurses in the Inpatient Room of the Tgk Chik Ditiro Regional General Hospital with a total sample of 83 nurses. The results showed that 37 respondents were 20-30 years old (45\%), 38 people had S1 education $(46 \%), 50$ respondents were male $(60 \%)$ and 56 respondents were civil servants. $(67 \%)$, respondents who did not practice hand hygiene were 50 people $(60 \%)$. The results of statistical tests obtained $\mathrm{p}$-value $=$ $0.000<\alpha 0.05$, which means there is a relationship between nurses in performing hand hygiene on the incidence of phlebitis. The conclusion is that there is a relationship between nurses' entries in performing hand hygiene on the incidence of phlebitis in the Tgk. Chik Ditiro Sigli, Pidie Regency. Suggestions are expected that the hospital should conduct socialization and training on hand hygiene more often in an effort to reduce the incidence of phlebitis and hopefully nurses will be more obedient in carrying out hand hygiene in accordance with the rules / SOP that have been set at the hospital, regarding hand hygiene.
\end{abstract}

Keywords: Nurse Compliance, Hand Hygiene, Phlebitis 


\section{PENDAHULUAN}

Menurut data WHO, prevalensi infeksi terkait layanan kesehatan di negara maju bervariasi antara 3,5\% dan $12 \%$, sedangkan di negara berkembang antara 5,7\% dan 19,1\%. Jumlah kejadian phlebitis di Indonesia masih tinggi, sebanyak 50,11\% untuk Rumah Sakit pemerintah, dan 32,70\% untuk Rumah Sakit Swasta ${ }^{1}$.

Infeksi nosokomial merupakan salah satu penyebab utama dari meningkatnya angka morbiditas dan mortalitas, yang dapat menghambat proses penyembuhan sehingga mengakibatkan masalah baru dalam bidang kesehatan, antara lain meningkatnya hari rawat dan bertambahnya biaya perawatan serta pengobatan pasien di rumah sakit. Phlebitis merupakan Infeksi nosokomial yaitu infeksi oleh mikroorganisme yang dialami oleh pasien yang diperoleh selama dirawat di rumah sakit dengan manifestasi klinis yang muncul sekurangkurangnya $3 \times 24$ jam $^{1}$.

Phlebitis merupakan salah satu dari penyakit infeksi nosokomial, dimana infeksi nosokomial adalah suatu infeksi yang diperoleh atau dialami oleh pasien selama dirawat di rumah sakit dan menunjukkan gejala infeksi baru setelah 72 jam pasien berada di rumah sakit serta infeksi itu tidak ditemukan atau diderita pada saat pasien masuk ke rumah sakit. Suatu rumah sakit dapat dikatakan memenuhi standar pelayanan minimal rumah sakit apabila prevalensi kejadian infeksi nosokomial kurang dari atau sama dengan $1,5 \%{ }^{2}$.

Tingginya angka kejadian infeksi phlebitis menyebabkan izin operasional sebuah rumah sakit dicabut dikarenakan mutu pelayanan rumah sakit yang kurang baik dan beban kerja atau tugas bertambah bagi tenaga kesehatan, dapat menimbulkan terjadinya tuntutan menurunkan citra dan kualitas pelayanan rumah sakit ${ }^{2}$.

Menurut penelitian Hasanah (2017) di Jakarta didapatkan bahwa penelitian yang dilakukan di ruang rawat anak salah satu RS di Jakarta mengidentifikasi jenis terapi intravena sebagai salah satu faktor yang berkontribusi terhadap kejadian phlebitis pada anak. Risiko phlebitis akan meningkat setelah 24 jam pemasangan dan dilaporkan risikonya meningkat di ruang rawat intensif ${ }^{3}$.

Kejadian phlebitis disebabkan oleh banyak faktor antara lain adalah kurangnya tehnik aseptik sehingga menyebabkan kontaminasi mikroorganisme saat pemasangan infus, ketidaksesuaian ukuran IV kateter dengan vena, jenis cairan (PH dan osmolaritas) dan waktu kanulasi yang lama. Infusion Nursing Standards of Practices merekomendasikan bahwa level phlebitis yang harus dilaporkan adalah level 2 atau lebih sedangkan angka kejadian yang direkomendasikan oleh Infusion Nurses Society (INS) adalah $5 \%$ atau kurang, dan jika ditemukan angka kejadian phlebitis lebih dari $5 \%$, maka data harus dianalisis kembali terhadap derajat phlebitis dan kemungkinan penyebabnya untuk menyusun pengembangan rencana peningkatan kinerja perawat ${ }^{4}$.

Studi di Amerika Serikat menunjukkan tingkat kepatuhan perawat melakukan cuci tangan sekitar 50\% dan di Australia sekitar 65\% dimana angka tersebut berpotensial menimbulkan kejadian infeksi pada pasien termasuk kejadian phlebitis. Hal ini menjadi tantangan yang cukup berat bagi tim pengendali infeksi rumah sakit untuk mempromosikan program cuci tangan. Perawat yang bekerja di rumah sakit sangat beragam baik tingkat pendidikan, umur, masa kerja maupun tingkat pengetahuannya. Perbedaan karakteristik ini tentunya akan berpengaruh terhadap penguasaan ilmu pengetahuan, keterampilan dan sikap profesional seorang perawat dalam menjalankan perannya sebagai perawat ${ }^{5}$.

Phlebitis merupakan salah satu infeksi yang didapat dirumah sakit terkait dengan layanan kesehatan atau yang disebut dengan infeksi nosokomial ${ }^{6}$. 
Data di Indonesia didapatkan pada tahun 2016 salah satunya di RSUD Setyonegoro Kabupaten Wonosobo mengalami peningkatan dari $0,37 \%$ menjadi $1,48 \%$ kasus, hal ini disebabkan karena masih banyak ditemukan praktik tentang teknik aseptik petugas kesehatan masih kurang seperti kebiasaan mencuci tangan sebelum mengobati, merawat ataupun memegang pasien. Penelitian Nurjanah (2011) di ruang rawat inap dewasa RSUD Tugurejo Semarang dari 70 responden, terjadi Phlebitis sebanyak 38 orang $(54,3 \%)$. Hasil penelitian tersebut menunjukkan 12 responden $(17,1 \%)$ phlebitis pada hari ke tiga ${ }^{7}$.

Berdasarkan data survelans bulan Januari 2018 tentang pemasangan infus rumah sakit umum daerah dr. Zainoel Abidin Banda Aceh (2018) di Ruang Rawat Inap Seurune I, didapatkan jumlah angka kejadian phlebitis yaitu 20,9\% .

Berdasarkan survei awal yang peneliti lakukan diperoleh data dari Rumah Sakit Umum Daerah Tgk Chik Ditiro Sigli Kabupaten Pidie bahwa angka kejadian phlebitis selama 3 tahun terakhir mengalami peningkatan dimana pada tahun 2018 angka kejadian phlebitis sebanyak 3.923 kasus, pada tahun 2019 sebanyak 1.780 kasus dan pada tahun 2020 periode Januari sampai dengan Agustus tercatat sebanyak 9.646 kasus.

Upaya yang dilakukan untuk mencegah dan mengendalikan phlebitis di Rumah Sakit Umum Daerah Tgk Chik Ditiro Sigli Kabupaten Pidie diantaranya adalah meningkatkan fasilitas pendukung serta standar prosedur operasional tentang cuci tangan yang benar. Tenaga keperawatan juga diberikan pelatihan manajemen insersi intra vena secara bertahap, namun demikian phlebitis masih menjadi masalah utama infeksi dikarenakan tindakan Hand hygiene yang dilakukan belum sepenuhnya sesuai prosedur sehingga menjadi satu penyebab terjadinya infeksi phlebitis.

Berdasarkan fenomena diatas maka peneliti tertarik untuk melakukan penelitian tentang Pengaruh Kepatuhan Perawat Dalam Melakukan Hand hygiene Terhadap Kejadian
Phlebitis Di Ruang Rawat Inap Rumah Sakit Umum Daerah Tgk Chik Ditiro Sigli Kabupaten Pidie.

\section{METODE PENELITIAN}

Penelitian ini menggunakan metode penelitian analitik dengan pendekatan crossectional yaitu cara pendekatan, observasi atau pengumpulan data sekaligus pada suatu saat, dimana pengumpulan data variabel Dependen dan Independen dilakukan penelitian disaat yang bersamaan. Populasi dalam penelitian ini adalah semua perawat di Ruang Rawat Inap Rumah Sakit Umum Tgk Chik Ditiro Sigli Kabupaten Pidie berjumlah 475 orang. Pada penelitian ini jumlah sampel yang diambil adalah sebanyak 83 perawat dengan menggunakan teknik Proportional Random Sampling. Penelitian dilakukan di Ruang Rawat Inap Rumah Sakit Umum Daerah Tgk Chik Ditiro Sigli Kabupaten Pidie. Penelitian dilakukan mulai bulan Juli sampai dengan November 2020.

Instrumen pengumpulan data yang digunakan dalam penelitian ini adalah lembar observasi tentang kejadian phlebitis dan observasi kepatuhan perawat dalam melakukan hand hygiene yang sudah dibakukan oleh peneliti sebelumnya yaitu Nurahmani ${ }^{9}$ dengan skor hasil keseluruhan uji validasinya memenuhi taraf signifikan $5 \%$ yaitu diatas nilai r-tabel 0,361 sedangkan hasil uji reliabilitas diperoleh nilai Cronbach's alpha0,723 > nilai $\mathrm{r}$ tabel 0,361 .

Etika penelitian yang dilakukan oleh peneliti adalah sebagai berikut :

1. Menghormati harkat dan martabat manusia (respect for human dignity)

2. Menghormati privasi dan kerahasiaan subjek penelitian (respect for privacy and confidentiality)

3. Keadilan dan inklusivitas (respect for justice and inclusiveness)

4. Memperhitungkan manfaat dan kerugian yang ditimbulkan (balancing harms and benefits $)^{10}$. 
Tahap pengumpulan data dalam penelitian ini adalah sebagai berikut:

a. Peneliti meminta kesediaan responden untuk berpartisipasi dalam penelitian dengan menandatangani lembar persetujuan responden.

b. Selanjutnya peneliti melakukan penelitian dengan menggunakan lembar observasi.

c. Untuk saat pandemic Covid-19 maka proses penelitian dilakukan sesuai dengan prosedur covid yang telah ditetapkan dirumah sakit.

Pada penelitian ini pengolahan dan analisa data dapat dilihat sebagai berikut :

1. Pengolahan data

Data yang telah didapatkan akan diolah dengan tahap Editing, Coding, Transfering dan Tabulating ${ }^{11}$.

2. Analisa Data

\section{a. Analisa Univariat}

Analisa data dilakukan untuk masing-masing variabel yaitu dengan melihat persentase dari setiap tabel distribusi frekuensi.

b. Analisa Bivariat

Untuk menguji hipotesa dilakukan analisa statistik dengan mengunakan uji data kategori Chi square Test $\left(X^{2}\right)$ pada tingkat kemaknaannya adalah 95\% (P $\leq 0,05)$ sehingga dapat diketahui ada atau tidaknya perbedaan yang bermakna secara statistik, dengan menggunakan program komputer. Melalui perhitungan uji Chi Square selanjutnya ditarik suatu kesimpulan bila nilai $\mathrm{P}$ lebih kecil atau sama dengan nilai alpha $(0,05)$ maka Ho ditolak dan Ha diterima.

\section{HASIL PENELITIAN}

\section{A. Analisa Univariat}

Tabel 1. Karakteristik Responden, Kejadian Phlebitis dan Kepatuhan Perawat Diruang Rawat Inap RSUD Tgk.Chik Di Tiro (n=100).

\begin{tabular}{lcc}
\hline Umur Responden & f & Persentase \\
\hline 20- 30 Tahun & 37 & 45 \\
31 - 40 Tahun & 26 & 31 \\
> 40 Tahun & 20 & 24 \\
\hline Pendidikan & f & Persentase \\
\hline S2 & 8 & 10 \\
S1 & 38 & 46 \\
D-III & 37 & 55 \\
\hline Jenis Kelamin & f & Persentase \\
Laki-Laki & 50 & 60 \\
Perempuan & 33 & 40 \\
\hline Status Pekerjaan & f & Persentase \\
\hline PNS & 56 & 67 \\
Bakti & 24 & 29 \\
Honorer & 3 & 4 \\
\hline Kejadian Phlebitis & f & Persentase \\
\hline Tidak Phlebitis & 38 & 46 \\
Phlebitis & 45 & 54 \\
\hline Kepatuhan & f & Persentase \\
Perawat & & \\
\hline Tidak Patuh & 50 & 60 \\
Patuh & 33 & 40 \\
\hline
\end{tabular}

Berdasarkan hasil penelitian dapat dilihat bahwa mayoritas responden berumur 20-30 Tahun sebanyak 37 orang (45\%). Berdasarkan pendidikan mayoritas responden berpendidikan berpendidikan S1 sebanyak 38 orang (46\%), berdasarkan jenis kelamin mayoritas responden berjenis kelamin laki-laki sebanyak 50 orang (60\%) sedangkan berdasarkan status pekerjaan mayoritas responden berstatus sebagai PNS sebanyak 56 orang $(67 \%)$.

Hasil penelitian yang dilakukan terhadap 83 responden berdasarkan variabel kejadian phlebitis dapat dilihat bahwa mayoritas responden mengalami phlebitis yaitu 45 orang (54\%) dan berdasarkan variabel kepatuhan perawat dalam melakukan hand hygiene dapat dilihat bahwa mayoritas responden tidak patuh dalam melakukan hand hygiene yaitu 50 orang $(60 \%)$. 


\section{B. Analisa Bivariat}

Tabel 2. Hubungan Kepatuhan Perawat Dalam Melakukan Hand hygiene Terhadap Kejadian Phlebitis Diruang Rawat Inap RSUD Tgk. Chik Di Tiro

\begin{tabular}{|c|c|c|c|c|c|c|c|}
\hline \multirow{3}{*}{$\begin{array}{l}\text { Kepatuhan } \\
\text { Perawat }\end{array}$} & & $\begin{array}{l}\text { Keja } \\
\text { Phle }\end{array}$ & $\begin{array}{l}\text { dian } \\
\text { bitis }\end{array}$ & & \multirow{2}{*}{\multicolumn{2}{|c|}{ Jumlah }} & \multirow{3}{*}{$\begin{array}{c}p \\
\text { (value) }\end{array}$} \\
\hline & \multicolumn{4}{|c|}{$\begin{array}{c}\text { Phlebitis Tidak } \\
\text { Phlebitis }\end{array}$} & & & \\
\hline & $\mathbf{f}$ & $\%$ & $\mathbf{f}$ & $\%$ & f & $\%$ & \\
\hline Tidak Patuh & 32 & 64 & 18 & 36 & 50 & 100 & \\
\hline Patuh & 6 & 18 & 27 & 82 & 33 & 100 & 0,000 \\
\hline Total & 38 & & 45 & & 83 & & \\
\hline
\end{tabular}

Berdasarkan hasil penelitian tentang hubungan kepatuhan perawat dalam melakukan hand hygiene terhadap kejadian phlebitis di ruang rawat inap RSUD Tgk. Chik Di Tiro menunjukkan bahwa dari 50 responden yang tidak patuh melakukan hand hygiene mayoritas terjadi phlebitis yaitu 32 orang (64\%) dan dari 33 responden yang patuh melakukan hand hygiene mayoritas tidak ada kejadian phlebitis yaitu 27 orang $(82 \%)$.

Berdasarkan hasil analisis uji statistik ChiSquare diperoleh nilai $p$-value $=0,000<\alpha 0,05$, yang artinya ada hubungan antara kepatuhan perawat dalam melakukan hand hygiene terhadap kejadian phlebitis diruang rawat inap RSUD Tgk. Chik Ditiro.

\section{PEMBAHASAN}

\section{Kejadian Phlebitis}

Kejadian phlebitis diruang rawat inap RSUD Tgk. Chik Di Tiro masih tergolong tinggi. Dari data tersebut dapat kita lihat bahwa angka kejadian phlebitis masih perlu perhatian khusus karena masih dalam katagori banyak terjadi pada pasien. Selain harus terus melakukan hand hygiene oleh perawat, pasien rawat inap yang mengalami phlebitis harus segera mendapatkan penanganan segera dengan menghentikan dan melepas infus, mengkompres dengan air panas, mengkaji nadi di daerah yang mengalami phlebitis.
Phlebitis merupakan inflamasi vena yang disebabkan oleh iritasi kimia maupun mekanik. Hal ini ditunjukkan dengan adanya daerah yang merah, nyeri dan pembengkakan di daerah penusukan atau sepanjang vena. Insiden phlebitis meningkat sesuai dengan lamanya pemasangan jalur intravena. Komplikasi cairan atau obat yang diinfuskan (terutama PH dan tonisitasnya), ukuran dan tempat kanula dimasukkan. Pemasangan jalur IV yang tidak sesuai, dan masuknya mikroorganisme pada saat penusukan $^{12}$.

Menurut penelitian Sumara (2017) didapatkan hasil bahwa Berdasarkan data penelitian menunjukkan responden yang mengalami kejadian phlebitis sebanyak $56.25 \%$, dan responden yang tidak mengalami kejadian phlebitis sebanyak $43.75 \%{ }^{13}$.

Dari hasil penelitian maka peneliti berpendapat bahwa kejadian phlebitis mayoritas berada pada kategori tidak phlebitis ini dikarenakan pasien jarang menggerakkan tangan yang dipasang infus sehingga pasien tidak mengalami phlebitis atau peradangan di tempat pemasangan infus dan tidak nyeri pada tangan yang dipasang infus selain itu perawat sebelum memberi tindakan pemasangan infus melakukan hand hygiene atau mencuci tangan serta memakai sarung tangan sehingga dapat terhindar dari bakteri atau kuman yang bisa terpapar ke pasien.

\section{Kepatuhan Perawat Dalam Melakukan Hand Hygiene}

Berdasarkan hasil penelitian tentang kepatuhan perawat dalam melakukan hand hygiene dapat dilihat bahwa mayoritas responden tidak patuh dalam melakukan hand hygiene. Di rumah sakit tindakan hand hygiene merupakan suatu tindakan dasar yang wajib dilaksakan oleh seluruh tenaga kesehatan terutama perawat yang sering kontak langsung dengan pasien yang ada di rumah sakit. Dengan melakukan tindakan hand hygiene yang baik dan benar, dan mencegah terjadinya cross infection (infeksi silang), sehingga dapat menurunkan angka kejadian infeksi nosokomial. 
Risiko phlebitis akan meningkat setelah 24 jam pemasangan dan dilaporkan risikonya meningkat di ruang rawat intensif. Semakin patuh seorang perawat dalam melakukan hand hygiene sebelum melakukan pemasangan infus maka akan semakin menurunkan angka kejadian phlebitis tetapi kepatuhan dalam melakukan hand hygiene bukan hanya satu-satunya yang dapat menurunkan angka kejadian phlebitis ${ }^{16}$.

Menurut penelitian Sunardi didapatkan bahwa hasil penelitian di ruang rawat inap Rumah Sakit Umum pada perawat mayoritas perawat terlihat patuh melakukan cuci tangan sebelum pemasangan infus yaitu sebanyak $65,8 \%$ dan perawat yang tidak patuh melakukan cuci tangan sebelum pemasangan infus yaitu sebanyak $(34,2 \%)^{14}$.

Menurut pendapat peneliti bahwa dilapangan masih banyak perawat yang tidak patuh dalam melakukan hand hygiene selain dikarenakan kesibukan merawat pasien juga dikarenakan mereka malas untuk melakukannya dimana mereka hanya melakukan hand hygiene apabila tangan benar-benar dalam keadaan kotor sehingga five moment tidak mereka laksanakan.

\section{Hubungan Kepatuhan Perawat Dalam Melakukan Hand hygiene Terhadap Kejadian Phlebitis}

Pada hasil penelitian didapatkan bahwa responden yang tidak patuh dalam melakukan hand hygiene mayoritas terdapat kejadian phlebitis.

Risiko phlebitis akan meningkat setelah 24 jam pemasangan dan dilaporkan risikonya meningkat di ruang rawat intensif. Semakin patuh seorang perawat dalam melakukan hand hygiene sebelum melakukan pemasangan infus maka akan semakin menurunkan angka kejadian phlebitis tetapi kepatuhan dalam melakukan hand hygiene bukan hanya satu-satunya yang dapat menurunkan angka kejadian phlebitis ${ }^{15}$.

Kepatuhan perawat dalam melakukan praktik cuci tangan sangat penting dilakukan karena ketidakpatuhan dapat menimbulkan dampak antara lain: penambahan diagnosa penyakit dan memperpanjang jumlah hari rawat selama di rumah sakit hingga dapat menyebabkan kematian bagi pasien, dapat menularkan kepada orang lain setelah meninggalkan rumah sakit bagi pengunjung, akan menjadi barier (pembawa kuman) yang menularkan kepada pasien lain dan diri sendiri bagi perawat dan menurunkan mutu pelayanan rumah sakit hingga pencabutan ijin operasional rumah sakit. Perawat memiliki pengaruh yang cukup besar terhadap terjadinya infeksi nosokomial karena perawat merupakan tenaga kesehatan yang paling banyak melakukan kontak dengan pasien dan berinteraksi secara langsung dengan pasien selama 24 jam. Upaya pencegahan infeksi nosokomial yang dapat dilakukan perawat adalah dengan meningkatkan kemampuan dalam menerapkan kewaspadaan standar (standar precaution) dengan komponen utamanya yang merupakan salah satu metode paling efektif untuk mencegah penularan patogen berkaitan dengan pelayanan kesehatan adalah dengan melakukan praktek kebersihan tangan (hand hygiene) ${ }^{16}$.

Menurut penelitian Lestari dengan judul Hubungan Kepatuhan Perawat Dalam Melakukan Hand hygiene Di Yogyakarta didapatkan bahwa harga koefisien nilai p-value sebesar $0,000<0,05$ dengan nilai keeratan 0,995 termasuk dalam kategori tinggi. Dari hasil tersebut dapat disimpulkan bahwa ada hubungan kepatuhan perawat dalam melakukan hand hygiene dengan kejadian phlebitis memiliki keeratan hubungan sebesar 0,995 yang artinya kategori tinggi ${ }^{17}$.

Dari hasil penelitian maka peneliti berpendapat bahwa ada hubungan antara kepatuhan perawat dalam melakukan hand hygiene terhadap kejadian phlebitis dimana hal tersebut juga didukung oleh faktor umur responden serta didukung oleh pendidikan responden yang mayoritas berpendidikan S1 dan mayoritas pekerjaan responden adalah sebagai PNS yang kemampuan tersebut didapatkan dari pengalaman responden menjadi perawat serta telah mampu mencegah kejadian phlebitis. Kepatuhan perawat 
dalam melakukan hand hygiene juga harus didasarkan pada kemauan dan motivasi yang kuat sehingga hal tersebut menjadi sebuah kebiasaan yang bernilai positif termasuk penurunan angka kejadian phlebitis.

\section{KESIMPULAN}

Berdasarkan penelitian yang telah dilakukan, maka diperoleh kesimpulan: Ada hubungan antara kepatuhan perawat dalam melakukan hand hygiene terhadap kejadian phlebitis diruang rawat inap RSUD Tgk. Chik Di Tiro.

\section{SARAN}

\section{Bagi Rumah Sakit}

Diharapkan kepada pihak rumah sakit untuk lebih sering melakukan sosialiasi dan pelatihan tentang hand hygiene untuk meningkatkan pengetahuan perawat tentang hand hygiene dan diharapkan adanya dukungan dan reward bagi perawat yang melaksanakan kepatuhan hand hygiene dengan baik supaya perawat di ruang rawat inap RSUD Tgk. Chik Di Tiro serta diharapkan kepada supervisi Komite PPI dapat lebih meningkatkan pengawasan kepada perawat dalam melakukan hand hygiene.

\section{Bagi Perawat}

Diharapkan agar lebih patuh dalam melakukan hand hygiene dan meningkatkan pengetahuan tentang pentingnya tindakan hand hygiene dan diharapkan agar lebih mematuhi peraturan/SPO yang ada di rumah sakit khususnya tentang hand hygiene.

\section{Bagi Peneliti Lain}

Untuk peneliti selanjutnya diharapkan agar dilakukan penelitian tentang kepatuhan hand hygiene dari sudut pandang pasien dan masyarakat serta hasil penelitian ini dapat digunakan peneliti selanjutnya untuk menindaklanjuti hasil penelitian ini dengan mengkaji faktor-faktor lainnya yang berkaitan dengan pelaksanaan hand hygiene.

\section{DAFTAR PUSTAKA}

1. Rodyah S.A.U. Hubungan Lingkungan Kerja Perawat Dengan Tingkat Kepatuhan Pelaksanaan 5 Momen Hand hygiene Di
Ruang Rawat Inap Rumah Sakit Umum Kaliwates PT Rolas Nusantara Medika Jember. 2015.

2. Pradini P.C.A. Faktor-Faktor Yang Berhubungan Dengan Kejadian Phlebitis Pada Pasien Rawat Inap Di RSUD Tugurejo Semarang Tahun 2016. 2016.

3. Hasanah O, Novayelinda R. Menurunkan Derajat Phlebitis Akibat Terapi Intravena Pada Anak Dengan Kompres Aloe Vera: Studi Pilot Pendahuluan. 2017;20(1). doi:10.7454/jki.v20i1.502

4. Nusdin. Hubungan Kepatuhan Perawat Melakukan Hand hygiene Terhadap Kejadian Phlebitis Di Ruang Perawatan Interna RS Pelamonia Makassar. AKRAB JUARA. 2018;3(3):176-183.

5. Suratun, Gustina, Sunardi. Pengaruh Kepatuhan Perawat Melakukan Cuci Tangan Sebelum Pemasangan Infus Terhadap Kejadian Phlebitis. Kesehatan Masy. 2018;2(3):1-14.

6. Silviawaty M, Putri DUP. Hubungan Cairan Infus Dan Lokasi Pemasangan Infus Dengan Kejadian Phlebitis Di Rumah Sakit DKT Bandar Lampung. Manuju Malahayati Nurs J. 2020;2(3):515-524.

7. Nurjanah, Kristiyawati \& Solechan. (2011). Hubungan antara lokasi penusukan infus dan tingkat usia dengan kejadian phlebitis di ruang rawat inap dewasa RSUD Tugurejo Semarang. Diunduh pada tanggal 03 Januari 2020

8. Yana.K. Gambaran Kejadian Phlebitis di Ruang Rawat Inap Seurune I Rumah Sakit Umum Daerah dr. Zainoel Abidin Kota Banda Aceh Banda Aceh: 2018.

9. Nurahmani. Faktor Yang Memengaruhi Perawat Terhadap Kepatuhan Dalam Melakukan Hand Hygiene Sebelum Dan sesudah Melakukan Tindakan DiRuang Inap RSUD Cut Meutia Langsa. Diunduh dari http://repository.helvetia.ac.id/2480/6/Nurah mani\%20\%281602011093\%29.pdf. 2018.

10. Notoadmodjo.S. Metodologi Penelitian Kesehatan. Jakarta: Rineka Cipta; 2010.

11. Budiarto E. Metodelogi Penelitian. Jakarta: EGC; 2012. 
12. Sepvi, A. Hubungan Lingkungan Kerja Perawat Dengan Tingkat Kepatuhan Pelaksanaan 5 Momen Hand Hygiene Di Ruang Rawat Inap Rumah Sakit Umum Kaliwates PT Rolas Nusantara Medika Jember. Jember: Program Studi Ilmu Keperawatan. 2015.

13. Sumara, Retno. Hubungan Lokasi Terapi Intravenus Dengan Kejadian Phlebitis. Surabaya: Jurnal Keperawatan Muhammadiyah. Volume 2 Nomor 1. Hal. 126 - 134. 2017.

14. Sunardi, S. Pengaruh Kepatuhan Perawat Melakukan Cuci Tangan Sebelum Pemasangan Infus Terhadap Kejadian Phlebitis. Jakarta: Poltekes Kemenkes. 2018.
15. Dewi.R.,Faktor Determinan Kepatuhan Kepatuhan Perawat Melakukan Praktik Cuci Tangan Jurnal Kesehatan Masyarakat Khatulistiwa Vol.4, No.3, 2017.

16. Wahyu, A. Kepatuhan Perawat Melakukan Cuci Tangan Selama Pelaksanaan Tindakan Keperawatan Di Bangsal Raudhah Dan IGD RS PKU Muhammadiyah. Yogyakarta: STIKes Aisyiyah. 2019.

17. Lestari, Hubungan Kepatuhan Perawat dalam Melakukan Hand hygiene dengan Kejadian Phlebitis di RSUD Wonosari, http://digilib.unisayogya.ac.id/4608/1/NAS KAH\%20PUBLIKASI_LESTARI\%202.pdf .2019 